Article

\title{
Lessons of the Pandemic for Family and School-The Challenges and Prospects of Network Education
}

\author{
Svetlana N. Vachkova ${ }^{1}\left(\mathbb{D}\right.$, Igor V. Vachkov ${ }^{2}$, Ivan A. Klimov ${ }^{1,3}$, Elena Yu. Petryaeva ${ }^{4}$ \\ and Valentina B. Salakhova ${ }^{1,5}$,*
}

check for updates

Citation: Vachkova, S.N.; Vachkov, I.V.; Klimov, I.A.; Petryaeva, E.Y.; Salakhova, V.B. Lessons of the Pandemic for Family and School-The Challenges and Prospects of Network Education. Sustainability 2022, 14, 2087. https:/ / doi.org/10.3390/su14042087

Academic Editor: Muhammet Usak

Received: 13 December 2021

Accepted: 31 January 2022

Published: 12 February 2022

Publisher's Note: MDPI stays neutral with regard to jurisdictional claims in published maps and institutional affiliations.

Copyright: (C) 2022 by the authors. Licensee MDPI, Basel, Switzerland. This article is an open access article distributed under the terms and conditions of the Creative Commons Attribution (CC BY) license (https:// creativecommons.org/licenses/by/ $4.0 /$ )
1 Institute of Urban Studies and Global Education, Moscow City University, 129226 Moscow, Russia; svachkova@mgpu.ru (S.N.V.); klimov_ivan@list.ru (I.A.K.)

2 Department of Psychology and Pedagogy of Distance Learning, Moscow State University of Psychology and Education, 123290 Moscow, Russia; VachkovIV@mgppu.ru

3 International Laboratory for Applied Network Research, HSE University, 101000 Moscow, Russia

4 Center for Analytical Research and Modeling in Education, Institute of Urban Studies and Global Education, Moscow City University, 129226 Moscow, Russia; petryaeva.elena@gmail.com

5 Department of Psychology and Pedagogy, Faculty of Humanities and Social Technologies, Ulyanovsk State University, 432017 Ulyanovsk, Russia

* Correspondence: salakhovavb@mail.ru

\begin{abstract}
The article contains the study results of the problems with the accessibility and safety of educational resources, applications, and tools of distance educational technologies for schoolchildren during the period of distance learning. In the framework of the study, the focus was also on the satisfaction of the subjects of educational relations with the services of providers and the support system for educational institutions during the COVID-19 pandemic in Moscow. The article identifies the key challenge to contemporary education-are schools capable of reworking and integrating all the achievements and breakthroughs of distance learning? The results show that when implementing distance learning, it is necessary to take account of the threats and risks that it entails-(1) the barrier of technological innovation; (2) the barrier of social factors; (3) the barrier to physical and psychological health; (4) the barrier of digital didactics; (5) the barrier of legal regulation; (6) the barrier of an inclusive environment. The study results can become the basis for the preparation of proposals and the development of recommendations to provide access to high-quality education for all schoolchildren in the context of distance learning.
\end{abstract}

Keywords: sustainability of the educational process; challenges and prospects of contemporary education; inclusive educational environment; social and digital inequality; distance learning; e-learning; online learning

\section{Introduction}

The 2020 coronavirus pandemic has caused the largest disruption to the entire educational system in human history. More than 1.5 billion students in more than 190 countries have been excluded from the education process. The shutdown of schools and other educational institutions affected $94 \%$ of the world's student population [1]. This pandemic, among many socio-economic and political consequences, had a huge impact on the educational system in general and on all subjects of the educational process in particular (students, teachers, and parents) [2-6]. The decision to switch to remote work and education, made by the governments of many countries, meant the implementation of these activity types exclusively with the help of digital resources. In turn, this revealed certain disadvantages of the educational models of each country, and it actualized the problem of social and digital inequality among the population [7].

"The digital gap means differences in the material, cultural and cognitive resources required to use ICT effectively. Historically, the research of the digital gap has focused on 
differences in physical access to and ownership of ICT tools... However, equal access does not mean equal opportunities. Indeed, even when there is an opportunity to learn about the world, to participate in online communities, or to develop a career plan, the students from socially and economically disadvantaged families may not know how technologies can help raise their social status. They may not have the knowledge and skills required to participate in Massive Open Online Projects (MOOCs), to use e-government websites, open educational resources, etc." [8].

Today, one of the acute research issues posed to the world's scientific community is the issue of developing network-based teaching and learning. Researchers around the world are engaged in studies on the question of how education reacts to the challenges of a profoundly new situation where distance teaching and learning has become the only way to obtain and acquire knowledge. An initiative launched by the consortium of participants of the World Education Leadership Symposium and the international project World School Leadership Study (WSLS) is one example of an international project that is aimed at collecting and analyzing the difficulties that are experienced by all educational stakeholders due to the COVID-19 pandemic and the massive switch to distance learning modes. The aspiration of the whole scientific community to process the global risks and challenges that have been outlined by COVID-19 has contributed to the fact that today, there is a great number of studies dedicated to distance education and the prospects of its development, in a search for effective solutions for educational tasks during the pandemic.

In the spring of 2020, due to the global situation caused by COVID-19, all educational institutions of Moscow had to shift to teaching by means of distance technologies and e-learning. Schools have taken a number of measures to ensure access to education for every student, as follows:

- $\quad$ Aiding households with two or more children by providing them with computers and tablets to access educational applications and distance communication services;

- $\quad$ Setting up non-linear schedules so that children of one household could study using one computer;

- $\quad$ Supporting students and their parents via messengers.

During the pandemic, Moscow's schools have been actively using the resources and tools provided by the Moscow Electronic School (the MES). The MES provides teachers and students with lesson scenarios, electronic textbooks, interactive applications, and tests on different subjects. At the beginning of the pandemic, there were 2968 applications uploaded to the MES (1975 applications approved after moderation) that were developed by 21 third-party companies. The MES allows teachers to create homework assignments for any selected lesson in a digital form. The grades for fulfilled assignments are indicated in an electronic diary.

In March 2020, an online school was launched in Moscow, offering video lessons for students in Grades 5-11 on more than 15 subjects, from Physics to Fine Arts. The online school engaged more than one hundred teachers of Moscow, including authors of textbooks and methodological guides and experts on unified state examinations. Teachers and parents of primary school students were offered more than 50,000 ready-made assignments on three subjects-Russian language, Mathematics, and Environment. These assignments were developed taking into account the Federal State Educational Standards.

However, the forced delivery of teaching using distance technologies highlighted the fact that education was not equally available to all students with regard to the organizational and technical equipment. Not all students had the following [9]:

- Personal devices (computers, tablets, smartphones) to ensure full-fledged access to educational applications and communication tools;

- Video cameras for full-featured involvement in online lessons;

- Stable high-speed Internet connection at their homes;

- $\quad$ Personal spaces for studies when all family members are home. 
The delivery of distance education at the quality level was hindered by the technical issues of providing uninterruptable access to learning data systems. Multi-child and low-income households were particularly at risk.

The described problems of providing basic education to the students of Moscow's schools has become a factor in the overall anxiety of the city's residents. Failure to ensure access to educational resources due to organizational or technical issues is a violation of the constitutional human right to education (Article 43 of the Constitution of the Russian Federation, Article 5 of the Federal Law No. 273, dated 29 December 2012 “On Education in the Russian Federation").

The key problem of this study was to analyze the issue of accessibility and safety of educational resources and applications, the tools of distance learning technologies for students during distance and online learning, students' satisfaction of the providers' services, and schools' support systems during the high-alert mode due to the threat of spreading the coronavirus infection in Moscow.

Distance learning is a form of providing education where a teacher and a student interact over a distance using information technologies. During distance learning, a student studies independently according to the developed curriculum, watches webinar recordings, solves tasks, asks for teacher's advice in an online chat, and submits their work for revision on a periodic basis.

Online or electronic learning is a logical extension of distance learning that supports acquiring knowledge and skills by means of a computer or another gadget connected to the Internet in the format of "here and now". It is considered a logical extension of distance learning. The word "online" indicates the method of acquiring knowledge and the type of communication with the students. During online learning, a student watches lectures online or as a recording, takes interactive tests, exchanges files with their tutor, communicates with classmates and teachers in chats, completes assignments, and so forth.

\section{Theoretical Review}

The problem of the digital gap in terms of the inequality of educational opportunities caused by the pandemic has been considered in the works of researchers such as S.M. Gonzalez-Betancor, A.J. Lopez-Puig and M.E. Cardenal [10], D. Ferguson [7], N. Iivari, S. Sharma and L. Venta-Olkkonen [4], Y. M. Tang [11], K. Srijamdee and P. Pholphirul [12], E. Beaunoyer, S. Dupere and M. J. Guitton [13], and others. Based on the experiences of 21 EU countries, the authors have concluded that the possibility of using IT technologies at home significantly impacts the development of students' digital literacy as well as the success of distance teaching and learning, while the influence of the social aspects does not matter at all (Belgium, Czech Republic, Denmark, France, Estonia, Greece, Ireland, Poland, Spain, and Sweden). However, in some countries, for example, in Slovakia, Sweden, and Estonia, the success of the distance education process using IT technology is influenced by both the socio-economic status of the family (income level, education level of parents, social status of the parents, etc.) and the school [10]. The authors argue that it is impossible to talk about the digital literacy of students without providing them with the necessary equipment. It has also been emphasized that while the technical accessibility of IT technologies can be provided by the family, it is the school that should be responsible for the quality of students' skills in IT technologies. The authors conclude that as a result of the first wave of the pandemic, all EU countries faced the problems of a digital gap due to the lack of computer equipment among the students, low digital literacy of the teachers and parents, and poor quality and performance of educational platforms.

"In the United States, in schools with high socioeconomic status, almost every 15-year-old student has a computer at home to work, while in less prosperous schools, only $75 \%$ of students of the same age have it at home. In Peru, the gap is even more significant, with $88 \%$ of students in privileged schools versus $17 \%$ in disadvantaged schools.

... In Austria, Iceland, Luxembourg, New Zealand, the United Kingdom and the United States, the ratio between students and computers <in schools> is 1.25 or higher, while 
in Albania, Brazil, Greece, Kosovo, Montenegro, Morocco, Turkey and Vietnam, there is only one computer for every 4 students (the ratio is 0.25 ) or even less.

... On average across OECD countries, only half of children are enrolled in schools with effective online learning platforms. In Singapore and Denmark, 90\% of students are enrolled in schools with a convenient platform to support online education, while in Luxembourg and Japan the corresponding index is lower than 30\%» [14].

The studies by Y. M. Tang [15], L. Saikkonen and M. T. Kaarakainen [16], and Van W. Lancker and Z. Parolin [17] included research findings on students' and teachers' attitudes to distance teaching and learning. These authors have identified five factors that influence the readiness of students to distance learning - technological readiness, unaided learning, monitoring of students, motivation for learning, and self-efficacy of online communication. Teachers can use these factors and develop the basic principles of context-based learning, teaching strategies, classroom environment, assessment methods, and so forth.

\subsection{Distance Education: An International Analysis of Practices}

The analysis of international practices shows that the crisis activated the development of innovative approaches in the teaching and learning processes. The innovations affected students, teachers, parents, as well as heads of educational institutions. The governments have sought to overcome the barriers to technological and wealth inequality and to ensure equal access to education [18-20].

In France, the epidemiological situation served as a stimulus to establish a National Center for Distance Education (CNED), an online portal called "Ma classe à la maison". This portal is not only a collection of learning resources but also a learning tool with the architecture and structure aimed to help students learn new subject content. Technological and methodological support of the portal is provided by the CNED services, which increases teachers' productivity. Moreover, the subject content is stored in digital environments-internal school networks such as Environment Numérique de travail, EcoleDirecte, ProNote, and so on. The teaching and learning process is also supported by the mass media; television and radio broadcasting agencies (France Télévisions, Radio France, and Arte и and National Education) provided services of podcasting, streaming, and broadcasting via national websites and platforms.

An efficient practice of distance education has been established in Austria. On the website of the Austrian Ministry of Education, there is a specialized section for students, teachers, and parents providing up-to-date information on distance teaching and learning during the pandemic. As learning platforms, Austrian's educational institutions use Moodle and LMS, Microsoft, and Google. In addition, the Ministry of Education developed a content platform, Eduthek. There is also a portal providing in-service training for teachers and administrative staff of educational institutions in the field of distance education. Special mention should be made of the advisory support to all educational stakeholders organized by the Austrian government. It is provided $24 / 7$ by school psychologists. Support is available in 23 languages, which removes the language barrier for its clients.

In the United Kingdom, the activities aimed at organizing distance education have been undertaken in several directions, as follows:

- A large-scale work was carried out on developing innovative teaching and learning technologies, and several educational platforms have been launched (Hungry Little Minds campaign, BBC “Tiny Happy People campaign”, National Literacy Trust Family Zone);

- $\quad$ A reform of the state approach to the school education system as a whole was implemented;

- At the government level, constant monitoring of ensuring the children's right to education was conducted; data is being collected on the operation of online platforms; - Monitoring of the operation of mobile and Internet providers.

In Columbia, a digital platform of the Ministry of Education, "Aprender digital", was established with more than 80,000 learning resources arranged by grade and offered in 
different formats (games, videos, etc.). The platform is available for teachers, principals, and other educational stakeholders and covers pre-school, primary, and secondary general education. For households with no Internet access, the government developed a learning kit to study at home. In addition, TV and radio broadcasting within the territory of the country was organized via national channels for students of primary and secondary schools.

In the territory of Jamaica, at the initiative of its government and several ministries, a large system of distance education support was established and included the following:

- $\quad$ Learning kits for students with no access to the Internet were prepared;

- TV lessons and re-broadcasting were included in the educational process (such as "School is not OUT");

- $\quad$ Learning content was developed for children aged 0-5;

- Support was provided to school initiatives using Google Suite, Schoology, Edmodo, Zoom, Skype, and WhatsApp;

- Access was ensured to digital learning resources (One on One Educational Services, Cheetah, Book Fusion, Edufocal, Learning Hub, CSEC COVID-19 Toolkit, etc.)

The case of Kenya is of special interest. In Kenya, educational TV shows are broadcast on the Edu TV channel, which is simultaneously streamed via Youtube, and there is a Kenyan Educational Cloud curated by KICD. To solve the issue of Internet access, the Kenyan government launched a program using Google Loon stratospheric aerostats that carry 4G-LTE basic stations.

The international experiences in organizing distance education allow us to make a number of conclusions. All countries, without exception, have used every effort to maintain the educational process and provide teaching and learning in the online mode, including the development of national programs and strategies at the state level as well as their implementation, the provision of the constitutional right of a child to education throughout the country regardless of the student's category, the mobilization of digital educational platforms and the development of new educational resources, the creation of national libraries and databases of teaching and learning materials without restriction in access for all education stakeholders, and so forth.

\subsection{Experience in Organizing Online Education in Russia}

In Russia, as in other countries around the world, a set of measures was implemented to transfer the educational system to an online format. Large-scale studies and monitoring, revealing the specifics of organized measures, have been carried out both by the scientific community and by representatives of state authorities $[5,9,21-26]$.

\section{Materials and Methods}

The objective of this research was to study the issues of accessibility and safety of educational resources, applications, and distance-learning tools for school students during distance education, students' satisfaction of the providers' services, and the functioning of the schools' support systems during the high-alert mode due to the threat of spreading the coronavirus infection in Moscow.

\subsection{Data and Sources of Materials for the Analysis}

- Normative legal documents that regulate the access to quality education for all students of general educational institutions in Moscow;

- The MES data downloaded from the data analytics system (https:/ / analytics-edu.mos. ru accessed on 20 November 2021);

- Data of state and departmental statistics;

- Data of open Internet sources on learning applications for students;

- Data of open network communities of students' parents and school teachers on distance teaching and learning in Moscow;

- Data of Moscow's schools' websites; 
- Data of a specialized crowdsourcing Internet platform used to collect and discuss ideas in the sphere of education policy that reflect the results of public discussions on the delivery of distance education in Moscow's schools;

- $\quad$ Results of surveys of parents with children aged 6-15 years;

- $\quad$ Results of deep interviews with students of Moscow's school;

- Results of students' surveys;

- Results of interviews with experts on schools and distance education;

- Results of focus groups with Moscow's teachers engaged in distance teaching of classes with at-risk children (from multi-child or low-income households), as well as with school principals.

\subsection{Target Groups of the Study}

1. Students aged 6-15 years enrolled in the primary and basic general educational programs of Moscow's schools;

2. Students' parents;

3. Teachers of primary and basic general education of Moscow's schools;

4. Principals of Moscow's schools;

5. Experts in school education.

\subsection{Strategy and Methods of Collecting the Field Data}

The study was conducted from September 2020 to November 2020. From June 2020 to August 2020, students were on summer vacation.

The survey was conducted in a distance mode on the platform https: / www.preobra. $\mathrm{ru}$ / from 12 October 2020 to 28 October 2020. The questionnaire for primary school students was not electronic but in paper format.

Interviews and group discussions were conducted from 8 October 2020 to 24 October 2020 in-person and via distance technologies. The researchers switched to the distance mode due to the new wave of the pandemic and the lockdown of schools. Interviews were held using Zoom and Teams software.

The main methods of the research included surveys of parents' opinions, the surveys and interviews with students, the focus groups with teachers and leaders of general educational institutions, the interviews with experts, and analyses of the statistical data, school websites, posts on social media, and the MES data.

The empirical data were collected over several stages, as follows:

1. Survey of parents' opinions - the total number of respondents was 1064;

2. Survey of students' opinions - the total number of respondents was 856;

3. Group discussions (7) with teachers of primary and secondary schools-the total number of participants was 64;

4. Group discussions (4) with school leaders-a total of 34 participants;

5. Expert interviews - survey of specialists in the field of organization and management of school education, including independent experts-a total of 12 respondents;

6. Deep interviews with students-a total of 22 interviewees.

\subsection{Sampling}

We characterized the research sampling as cluster-based, proportional, and random. The sampling and the strategy of data collection consisted of several stages.

At Stage 1, we first compiled a list of Moscow's districts (10) and a list of the schools in each district (a total of 534). We selected from 1 to 4 schools in each district by random choice (using a random number generator) proportional to the total number of schools in each district. As a result, we selected 33 schools to participate in the study (ratio of 1 to 16).

At Stage 2, we generated a sampling for each school. We decided not to involve the youngest students (Grade 1). We divided the other grades into 3 categories-primary school students (Grades 2-4), secondary school students (Grades 5-9), and senior school students (Grades 10-11). The questionnaires for each category of students differed in the number of 
questions, while the content of the questions was almost identical. (The differences were due to the specifics of age and curriculum for the primary, secondary, and senior schools. The questionnaires for the youngest participants comprised only 8 questions and had a special design (pictures and large font).

We tried to interview from 10 to 15 students in each school and in each category, depending on the total number of students. The total number of respondents in each school ranged from 25 to 33 students. The sampling principles took into account the gender balance of the students and the type of household - "normal" households and households with difficult life situations (such as having a child with health limitations, multi-child households, households with foster children, and low-income households).

Stage 3 included a sampling of the students' parents-parents of primary school students (Grades 2-4), parents of secondary school students (Grades 5-9), and parents of senior school students (Grades 10-11). The sampling principles for the parents were the same as for the students. However, the researchers could not regulate the gender balance of the parents or the practice of sharing information about school activities among the parents. Some parents shared the questionnaire and engaged in the survey with parents who were not included in the initial sampling.

Stage 4 included a selection of teachers and school principals. We selected $4-5$ teachers of primary, secondary, and senior schools, and 1-2 school leaders or a member of the administrative staff. The researchers engaged them in group discussions.

At Stage 5, we checked the quality of the sampling and the quality of the filled-in questionnaires. The final data sample excluded the questionnaires that did not pass the quality and the sampling checks.

At Stage 6, we developed a strategy for additional research, as follows:

(a) A series of interviews with experts on school education;

(b) Deep interviews with students;

(c) Online panel discussion.

(a) The experts included principals of schools that deliver distance education, researchers of digital education, community leaders, heads of public organizations, specialists of blended learning, specialists working with children with health limitations, and psychologists. The sampling criteria were based on the qualification level of an expert in one or more topics of the study. The interview guidelines included questions that were similar for all participants and questions addressing the experts' unique experiences, knowledge, and specialization.

(b) Deep interviews with students were held in the form of personal conversations according to a structured informal guideline that followed the main content sections of the questionnaire. Participants of the deep interviews included the following:

- Children from low-income households; 1 primary school student and 4 general school students;

- Children from multi-child households; 2 primary school students and 4 general school students;

- $\quad$ Children from sports school; 2 general school students;

- Children with special educational needs; 2 primary school students and 2 general school students;

- Children not included in the previous categories; 2 primary school students and 2 general school students.

(c) From 12 October to 1 November 2020, using the preobra.ru platform, a panel discussion was organized in 3 subject sections - education management, practices of distance education, and family and distance education. Guidelines were developed for each of the sections. The participants of the discussions had an opportunity to answer the questions under discussion and discuss topics, evaluate statements, leave comments, and suggest their own ideas and theses. The discussions involved 110 participants-parents (including parents of multi-child households, parents of children with health limitations), 
teachers, and school leaders. The participants generated 126 messages, 375 comments, and 600 evaluations of suggested theses.

\subsection{Anonymization and Processing of the Study Results}

The empirical data were processed using SPSS Statistics software. Based on the results, we conducted a descriptive data analysis (calculation of frequency distributions), a comparative analysis of different categories of students and parents (different levels of education, "normal" households, and households in difficult life situations), as well as Spearman's correlation analysis.

The audio recordings of interviews with students and experts, as well as the materials of the group discussions were transcribed. The texts were anonymized according to the international and Russian standards of social research (AAPOR, ESOMAR, the Russian Society of Sociologists). The analysis included axial encoding and the systematization of encoded fragments of the interviews based on the conceptual tasks of the study.

\subsection{Topic-Based Structure of the Questionnaires and Guidelines}

The questionnaires and guidelines were developed taking into account the ages of the students, their gender, the specifics of the school curriculum, and the aspects of the psychological development of children and teenagers, as follows:

1. Questionnaire for students of Grades 2-4 (8-10 years) -9 questions;

2. Questionnaire for students of Grades 5-6 (11-12 years) - 33 questions;

3. Questionnaire for students of Grades 7-9 (13-15 years) - 39 questions;

The questionnaires for parents were identical regardless of the specifics of their children's education.

The questionnaires and guidelines included questions addressing the issue of transitioning Moscow's schools to the distance learning mode during the lockdown of 2020.

The topics of the questionnaires and guidelines included the following:

1. Social and demographic data, household specifics, type of education-informational;

2. Organizational and technical conditions of distance education in the spring of 2020;

3. Evaluation of the efficiency of the transition to the distance learning mode;

4. Competency in digital technologies, acquiring distance educational technologies, teaching and learning in the electronic mode;

5. Evaluating the study load and education quality, within extended education as well, during the period of distance learning, and the impact on health and emotional state of children;

6. Describing and evaluating the advantages and disadvantages of distance education, and the desired format of education in the future;

7. Evaluating the issue of unequal access to the learning opportunities for children from "normal" households and from households with difficult life situations;

The researchers had an opportunity to solve the latter of the described tasks. The following are the characteristics of the student respondents:

Students of Grades 2-4:

- "Normal" household-100 students;

- Multi-child household-108 students;

- Low-income household-20 students;

- Household with a child with health limitations-80 students;

- Foster child-12 students;

- Child enrolled in a sports school-17 students;

- Homeschooled child-14 students

- Students of Grades 5-9:

- "Normal" household-153 students;

- Multi-child household-147 students;

- Low-income household-38 students; 
- Household with a child with health limitations-87 students;

- Foster child-15 students;

- Child enrolled in a sports school-56 students;

- Homeschooled child-10 students

\subsection{Application of the Research Findings}

The findings of this research passed the Moscow City University's ethical commission and were published as a preprint available for assessment by peer researchers and professional discussion. The findings were used to elaborate the recommendations on distance education development for Moscow's educational management system.

\section{Results}

\subsection{The Period of Physical and Social Distancing of Children}

School closures due to the COVID-19 pandemic and the shift to online learning have reshaped the dynamics of student socialization, bringing out the problem of a "social crisis" in the formative development of contemporary children $[27,28]$. The experiences gained during the years of learning underlie the processes of formation and development of a child's personality $[29,30]$. The changed social situation of educational relations has created contradictory conditions for the mental development of children-the formation of new psychological constructs corresponding to each stage of the age period, and a set of new requirements for the formation of adaptive needs and abilities. In this regard, an important task in the implementation of online learning is to take account of the possible risks and threats associated with the transformation of educational relations (physical distancing and social isolation).

Different age groups of children, children from different categories of families, and parents have experienced the transition to online learning in different ways (Tables 1 and 2). The results of the study show that the risk group encompasses children (Grades 2-9) from large families and low-income families as well as children of all categories of families studying in Grades 2-4 (8-10 years old). Difficulties of the transition to online learning of these groups of children are associated with technical problems and the organization of the student's workplace. For younger students, problems associated with the formation of online learning social and emotional skills, attention, and behavioral control are added to the organizational difficulties.

Table 1. Sampling. Moscow City University. Parents' survey, $\mathrm{N}=1064$ people. Students' survey, $\mathrm{N}=856$ people. October 2020.

\begin{tabular}{cccc}
\hline & Family Categories & Students (\%) & Parents (\%) \\
\hline 1 & Multi-child family & 34 & 31 \\
\hline 2 & Low-income family & 6 & 9 \\
\hline 3 & Child with special needs & 19 & 13 \\
\hline 4 & With adopted child & 1 & 1 \\
\hline 5 & With a child attending a sports school & 10 & 10 \\
\hline 6 & With a child in homeschooling & 2 & - \\
\hline 7 & Ordinary child & 28 & 36 \\
\hline
\end{tabular}

The research data show that most students noted the existence of technical problems and difficulties (low technical readiness of electronic platforms and applications-Zoom, Teams, MESH, RESH, EZhD, and Yaclass-as well as the quality of these electronic resources on the Internet in general). The children indicated that conducting lessons and, accordingly, the development of educational material in educational programs completely depended on the quality of the electronic resources. "If I succeeded in entering the EZD, then I did my homework, if not, then I did not"; "The lesson just flew out of Zoom, for example, 
and the screen darkened", "It was very hard to hear the teachers and everything always kept freezing", "It was difficult to understand what and where, what was needed and the programs were loading for a very long time", "Hackers intervened the activity. Someone also wrote something not very good posing as you... We had a lot of such things... ", the children said in interviews.

Table 2. Children's attitude to online learning by family categories (\% of respondents in each category).

\begin{tabular}{|c|c|c|c|c|}
\hline Children: & $\begin{array}{l}\text { "A Child from an } \\
\text { Ordinary Family" }\end{array}$ & $\begin{array}{l}\text { "A Child from a } \\
\text { Large Family" }\end{array}$ & $\begin{array}{l}\text { "A Child from a } \\
\text { Low-Income Family" }\end{array}$ & $\begin{array}{l}\text { "A Child with } \\
\text { Limited Abilities" }\end{array}$ \\
\hline \multicolumn{5}{|l|}{ Conditions at home } \\
\hline Having one's own desk & 85 & 80 & 83 & 80 \\
\hline $\begin{array}{l}\text { Technical problems and difficulties } \\
\text { during online learning }\end{array}$ & 78 & 82 & 85 & 81 \\
\hline Having one's own computer & 23 & 15 & 19 & 16 \\
\hline \multicolumn{5}{|l|}{ Attitude to online learning } \\
\hline A child was dejected & 44 & 49 & 60 & 50 \\
\hline $\begin{array}{l}\text { It is difficult to master the material } \\
\text { in main subjects }\end{array}$ & 48 & 47 & 53 & 58 \\
\hline "Nothing good" in online learning & 66 & 68 & 74 & 72 \\
\hline Would not like to study online & 64 & 76 & 83 & 77 \\
\hline
\end{tabular}

Almost all schoolchildren pointed out the availability of one's own room and workplace for online learning. However, it was very difficult for children from large families to organize their presence online. If a brother and/or sister in the family studied in Grades 9-11 grades, then the priority in training was given to them. All students had technical means (computer/laptop/tablet/phone) for the implementation of online learning, but children from low-income families and large families had only a tablet and/or a phone and worked with the help of these gadgets. Children with special educational needs and "ordinary children" used a computer, a tablet, and/or a telephone in the process of online learning. It should be noted that these categories of children preferred either a tablet or a phone. "It is more convenient and mobile to use your phone", "You can walk around the house with it", "You can attend to your business", "You can stay in bed and turn on your phone and listen to the lesson", "You can turn on your phone and simultaneously do your homework on your computer", said the children.

All students consider the transition to online learning as a necessary and forced measure. Students noted their interest in this form only at the beginning of self-isolation (in March 2020) and explained it by the possibility of not going to school. However, after some time, this interest vanished (October 2020). The children noted the difficulty of mastering the educational material in the main subjects and constant fatigue and bad moods. In addition, there was a conniving attitude, anger, and frustration towards online classes. "The first two weeks I was interested, and then it became awful", "The interactive, the game form in the lessons was interesting. But that was at the beginning of the quarantine. Then it became uninteresting and boring", "It was hard to understand the subject and master information. The poor connection of the Internet made us always review the teacher's presentation again", said the children.

The data obtained indicate that most students have a negative attitude towards online learning. They assess the capabilities of these technologies as minimal and demonstrate a high degree of motivation and readiness for offline learning.

\subsection{Basis: Equipment and Workplace}

Due to the pandemic and the switch to distance education, there was a "school dispersion". It turned out to be distributed over many of the students' home spaces. 
Some of the first challenges that every family had to face were the solutions to technical problems and the organization of the student's workplace. The research shows that even for Moscow's residents it was a problem. More than half of the parents (57\%) said it was difficult to arrange a working environment for their children for the following reasons:

- $\quad$ Only two-thirds of students (62\%) had their own desk;

- $\quad$ More than a third of parents (39\%) noted that during the child's lessons, another family member was present in the same room;

- $\quad 11 \%$ of parents answered that their children did not have their own workplace (they had to study at the dinner table, on the sofa, etc.), and another $14 \%$ said that one of the family members let the children use their table (another $10 \%$ found it difficult to answer, while $4 \%$ chose the option "other").

Technical equipment also proved to be a source of stress and problems. It should be noted that parents and children were together in common family spaces where they also had to fulfill their working duties. The difficulties included the following:

- $\quad$ Only a quarter of students (25\%) had their own computer or laptop;

- $\quad$ Almost half of students (46\%) used mobile devices to participate in the lessons;

- $\quad 79 \%$ of the surveyed families had a dedicated Internet line at the beginning of the remote learning process;

- $\quad 36 \%$ of the families had to arrange the Internet connection or improve the connection quality;

- Parents also paid for access to the online services (20\%) and purchased the necessary software $(8 \%)$.

The lack of computer equipment and poor Internet connection became some of the leading topics during the focus group discussions with teachers and school principals. The latter called these some of the main problems of distance education. Often, there was only one PC for the whole family. Both parents and children had to use the only PC for their work and studies. The families with several children were affected the most. Often, computers that parents received at work for home use were inaccessible to the rest of the family members due to corporate security requirements.

The schools were able to find a reserve and distribute school equipment primarily to low-income and multi-child families. However, only a few households received such support while many more needed it. According to the survey data, only $6-7 \%$ of families received equipment as help and support; $2 \%$ of these families received it from schools, $3 \%$ from the employers of one of the parents, and $2 \%$ from relatives and friends.

It is worth noting that the majority of school principals who participated in the focus groups said that they received a large number of calls from parents from "ordinary" families with a request to provide a PC for the child. This means that the problem affected a much greater number of people, not only multi-child and low-income families. It was the schools that faced the request for the technical equipment for students' workplaces at home. At the same time, the educational spaces of the school equipped with the latest technology could not be used.

\subsection{Learning Interaction}

During the self-isolation period, the educational interactions between the teachers and students became almost completely mediated by the digital environment. However, services and programs did not always work stably. The overwhelming majority of parents $(87 \%)$ described some kinds of technical problems. Most often, they mentioned failures in the functioning of essential websites $(60 \%)$ and programs $(50 \%)$, failures in the Internet connection (54\%), and problems with sound (42\%). The schools and teachers had to quickly solve the most typical problems-how to integrate various digital services and devices with each other, and how to understand the nature of failures and, similar to a call center operator, give instructions to the children and their parents on how to connect to online lessons, services, and educational content. It is not surprising that among the disadvantages 
of distance education, the overwhelming majority of parents mentioned the loss of personal contact with the teacher ( $80 \%$ ) and insufficient communication with classmates (76\%).

The new way of teaching demanded from schools and teachers a radical change in the educational process and the maximum mobilization of both organizational and personal resources. The time for knowledge transfer was reduced; the direct contact between teacher and students became impossible; the search and selection of high-quality teaching and learning content began taking longer; the volume of individual work and personal consultations increased. In addition, online communication has become burdensomethere is too much of it, and too few opportunities to switch from it; people have experienced the syndromes of burnout, fatigue, and depression; new forms of bullying have emerged; the risks of cybersecurity breaches have increased.

Almost all of the teachers who participated in the focus groups reported a large number of requests for assistance from a psychologist. They noted that there were not enough psychologists in schools, provided that in the "time of peace", psychologists were also in great need. Particularly often, this issue was mentioned by the teachers of sports schools who said that the difficulties of self-isolation, the pandemic, and remote learning increased the stress of the children during preparation for competitions and qualification evaluations.

Another aspect of this issue is that the educational process became completely open to parents. "Parents experienced extreme stress due to the pandemic, due to their work and reduction of wages. The psychological well-being of their children and their school performance became an additional stress factor. All this spilled over on me and my colleagues", said one of the teachers who participated in the study. The school administration confirmed that the number of complaints from the worried parents grew exponentially. The main concerns and issues included the following: how will the educational process be structured, how to help one's child to understand a learning topic; how to prepare one's child for exams, how to prevent a student from missing out on the educational process, and how to help him/her to finish school with expectedly decent grades.

According to the teachers interviewed, the influence of parents was two-fold. On the one hand, they were forced to act as teachers' assistants. Not only did parents help their children to overcome the technical difficulties that they had, but they also supported and motivated them to study and do their homework. Therefore, the adults themselves required methodological assistance and/or facilitation from the teachers. On the other hand, the parents often dived too deeply in the educational process; they excessively supervised their children doing homework and prompted them during tests. This mainly applied to the parents of primary school and students in Grades 5-6.

The stress due to self-isolation, the need to adapt to learning from home, and the deeper involvement of parents in the educational process have generated a request for an individual approach to teaching and learning, and more so since it became possible to choose the learning format (at school or from home), the method (together with a teacher or independently), the pace, the amount of homework, the teacher and the platform, and so forth. However, judging by the statements of teachers from specialized schools, the most alarming was and remains the situation with families that have children with special needs. The difficulties are as follows:

- It is difficult for the children to remain involved and concentrate for a long period of time during an online lesson;

- The possibilities for teachers and psychologists to work with these children are severely limited;

- Parents are often either not ready or not able to do for their children what a specially trained teacher can do.

The research data shows that multi-member, low-income families and households that have children with special needs were much less able to provide their children with comfortable conditions for remote learning. The conditions for learning from home in these families were generally lower; the children did not have their own workplace or personal computer, and there was no opportunity to study in a private atmosphere (Table 3). 
Table 3. Parents' viewpoint: Children's home learning conditions. Parents' attitudes towards remote learning (\% of respondents in each category).

\begin{tabular}{|c|c|c|c|c|}
\hline Families: & "Ordinary" & "Multi-Child" & “With Low Income" & $\begin{array}{l}\text { "Child with } \\
\text { Special Needs" }\end{array}$ \\
\hline \multicolumn{5}{|l|}{ Home learning conditions } \\
\hline The child had his/her own desk & 66 & 58 & 52 & 57 \\
\hline $\begin{array}{l}\text { There were other people in the room } \\
\text { during a child's online session }\end{array}$ & 33 & 49 & 49 & 43 \\
\hline The child had his/her own PC & 30 & 20 & 25 & 19 \\
\hline \multicolumn{5}{|l|}{ Attitudetowards remote learning } \\
\hline The child was in a difficult emotional state & 32 & 42 & 43 & 40 \\
\hline $\begin{array}{l}\text { It is difficult to master the content of the } \\
\text { main subjects }\end{array}$ & 42 & 51 & 55 & 50 \\
\hline $\begin{array}{l}\text { There is "nothing good" in } \\
\text { remote learning }\end{array}$ & 44 & 56 & 63 & 54 \\
\hline $\begin{array}{l}\text { I would not like my child to } \\
\text { study remotely }\end{array}$ & 82 & 89 & 90 & 87 \\
\hline
\end{tabular}

In addition, parents of these households more often spoke about the difficult emotional and psychological state of their children. They were more worried that the quality of their children's knowledge would be lower since it was harder for their children to embrace the content of online lessons, concentrate during the lesson, and master the content of the basic school subjects. Therefore, it is not surprising that parents from large, low-income families and families that have children with special needs were much more strongly opposed to remote learning. These categories of parents especially urgently demanded the provision of the appropriate educational formats based on the capabilities of their children.

\subsection{The Quality of Teaching and Functions of School}

The study shows disturbing results. The forms and methods of distance education that were implemented during the pandemic threatened the traditional school functions, including teaching, socialization, communication with peers, ensuring the protection of the students' life and health, and so on.

The quality of knowledge was strongly influenced (and will be influenced) by the fact that it is impossible to switch from the home environment. The physical process of coming to school means a transition from one system of relationships (family) to another system of rules and relationships (school). The absence of this transition often disrupts students' concentration in the learning process. In addition, in case the environment at home is unfavorable, neither the teacher nor the school can compensate for this in any way.

Both the school principals and the interviewed teachers assumed that a serious threat to school education is the separation of its four basic functions-the function of knowledge transfer, the function of upbringing, the function of assistance in socialization, and the function of compensating inequality in access to education. During the period of teaching and learning from home, schools experienced a limited capacity to maintain a fully-functional approach to specific groups and categories of families and children.

The children were differentiated according to the criterion of educational motivation that was not associated with any family-specific factors. School principals gave examples of children from low-income or multi-child families who showed consistently high learning outcomes and engagement. On the contrary, for parents it was a source of anxiety: "Everyone in our family was under stress, my child did not want to get up for lessons, preparing homework turned into torture. I constantly yelled, grew tougher while he cried. And then I decided that school performance was not worth the well-being of our family" (parent of the "ordinary" family). All participants of the study considered the question of responsibility, defining who is 
responsible for developing students' motivation to learn (family or school?), very difficult to answer and to find a straightforward solution for (Table 4).

Table 4. Parents' viewpoint: Children's attitudes towards learning during self-isolation (\% of respondents in each category).

\begin{tabular}{ccccc}
\hline Families: & “Ordinary" & “Multi-Child” & “With Low Income” & $\begin{array}{c}\text { “Child with } \\
\text { Special Needs" }\end{array}$ \\
\hline $\begin{array}{c}\text { It was harder for the child to } \\
\text { embrace the content of the lessons }\end{array}$ & 66 & 58 & 52 & 47 \\
\hline $\begin{array}{c}\text { It was difficult for the child to } \\
\text { receive help from the teacher }\end{array}$ & 34 & 43 & 42 \\
\hline $\begin{array}{c}\text { The child became unwilling to do } \\
\text { his/her homework }\end{array}$ & 34 & 42 & 43 \\
\hline
\end{tabular}

Another indicator of the upsurge in problems and challenges within the educational process was the increase in the working hours of the teachers and school administration. Without exception, all the teachers who participated in the survey spoke about irregular working hours and the absence of days off during the spring of 2020. Teachers said that their students had different capabilities for using the technical equipment or receiving technical assistance from their parents. Due to this, they sent their homework not only during the day but also at night. Teachers had to meet some of the students in person in the street to physically hand over or receive their homework. The number of individual consultations, which were additionally provided by teachers to both children and parents, increased significantly. This factor seriously impacted the workload. "There was no chance to have a rest. After a month of such a work mode, I realized that I was not recovering after the weekends. I almost abandoned my household duties, my daughter cooked instead. When the school went on vacation, I slept for 12 h every day during the first week" (teacher).

To conduct online lessons, teachers needed a fully functional workplace at home. Schools allowed teachers to borrow school computers and place them at home. However, this was insufficient since teachers had to buy printers and scanners for preparing tasks and teaching materials, install better lighting, and attach webcams and headphones, as well as purchase more expensive Internet access. The time teachers spent working on the computer increased. More than half of the respondents complained of eyesight deterioration, back pain, and problems with the spine. It turned out that home chairs were not suitable for long hours at the computer desk. Many teachers did not have a computer chair.

It is justifiable to assume that the rapid restructuring of the educational process had a negative impact on the education quality. This issue was often suppressed by school principals and teachers. Most of them mentioned the absence of sufficient technical equipment in the families as the main barrier, "We will cope with the rest of it sooner or later, but with this, school is almost unable to help" (school principal).

Most parents spoke of a decrease in the quality of knowledge acquired by their children during the spring episode of distance learning - $46 \%$ spoke of a significant decrease, while $31 \%$ of parents said that the quality decreased but they were able to support it using some additional measures. A very small number of parents $(4 \%)$ noticed positive changes, while another $13 \%$ did not notice any significant changes or were undecided $(7 \%)$. One more important figure was that more than half of the adult participants of the survey responded that their children were not satisfied with their progress following distance learning (53\%); the opposite opinion was given by $33 \%$ of the respondents. The general opinion of the parents was that it was easier for their children to study in the traditional full-time format, not in the remote format $-91 \%$ versus $1 \%$. Only $6 \%$ did not notice any significant difference.

However, the schools faced another strategic challenge- the need to reassemble the training programs with regard to the broad possibilities the Internet offers for conducting lessons in various subjects, as well as the need to reassemble the criteria for learning 
outcome evaluations. From the point of view of both the parents and teachers, one of the key outcomes of learning at school is the development of a child's personal qualitiesresponsibility, independence, time management skills, and subjectivity in relation to the learning process. The pandemic and self-isolation did not develop these competencies but demonstrated the need for them (only $9 \%$ of parents mentioned the experience of their child growing independent as one of the positive outcomes of distance learning).

\subsection{Requirements for the Family}

Experiences of learning during the pandemic have shown that networked education also makes new requests to families. Apart from the increased requirements to the organizations of adequate workplaces and conditions, there were a number of other tasks. The main task was to provide support to the educational process (especially for primary school students) - to help cope with a difficult emotional state, create a schedule, solve technical problems, master the educational material, and so forth. Only $8 \%$ of parents said that there were no special problems or difficulties during the distance education format. The rest mostly spoke about the difficulties in mastering the educational material (67\%).

Since parents did not have any knowledge and/or experience in supporting the educational process of their children, they demonstrated ineffective ways of assisting in the educational process-distancing, overprotection, too deep an immersion in the education process, and doing homework.

High tension in the family became a fact. It was provoked by various circumstances, as follows:

- The children bothered each other during the lessons (42\%);

- The child did not have the required level of computer skills (42\%);

- There was an increased emotional state of the child (40\%);

- There were quarrels with the child; one could speak of a lack of mutual understanding $(24 \%)$.

In the discussions, specific situations in families and relationships between the spouses were mentioned. These affected the children and their participation in lessons, as well as their academic performance.

As parents became aware of the problems, there was an increasing demand for tutors and subject teachers who were ready to remotely support the children in networked education and who were helping to search for and work with the necessary Internet resources and additional educational computer programs.

Distance teaching deprived the children of a "supportive environment" and required from the students a high level of educational independence. The parents more often noted as problems the large amount of material that their children had to master on their own $(64 \%)$, a lack of communication and group work with the students (55\%), and a lack of help from the teacher (37\%). There was an increase in the number of cases when students could not cope with their homework; there was no opportunity to work at a computer, they had low motivation, stress, and burnout, or they did not understand the lesson topic. The schoolchildren themselves noted that during the period of distance teaching, they lost the opportunity to see the results of their classmates and compare themselves and their level of knowledge with others.

The technical skills of schoolchildren also became very important-the ability to cope with technical problems, to follow the rules of cybersecurity and communication on social networks, and to send homework in the form of photos and high-quality videos. The latter mainly affected sports schools, where children had to record their training or a performance program on video, for which grades were posted.

To help the children explore network educational opportunities, support their involvement in the learning process, and find ways to develop their independence and adapt the educational process to the individual characteristics of the child, the parents had to create the necessary conditions for work and efficient rest within the house. The challenge was 
to build closer and more complex relationships with the teachers and schools. This is the factor that has to be taken into account when planning future distance teaching.

\section{Discussion}

The research findings presented in this paper allow for identifying the key trends in the global transformation of distance learning and suggesting recommendations to increase the efficiency of distance learning.

\subsection{Mechanisms, Practices, Problems, and Barriers to Distance Instruction of Students}

Nationwide distance teaching and learning was forced by an external factor-the COVID-19 pandemic. In such conditions, the educational system must respond rapidly and create the conditions for accessible education for all students. Among the factors that accelerated the shift of Moscow's schools to the distance work mode were the following: the functioning of the MES, the connection of all school buildings to high-speed Internet, the availability of Wi-Fi spots, and providing most of the teachers with staff laptops.

The respondents of the study identified the advantages of distance learning, such as the following:

- Students and teachers are not bound to a specific workplace;

- Engaging highly qualified academic and teaching staff and the potential of collective creativity during Internet conferences;

- More intensified interactions of subject teachers and classroom teachers with students;

- Availability of detailed summaries of lessons and recordings of online lessons;

- Open access to all electronic resources and transparency of the teaching process for parents;

- Opportunity to revise the content that was not grasped at the first try during the lesson;

- More independence and free time for motivated students of general and senior schools and more opportunities for planning and learning at one's own speed;

- Studying by personalized training programs;

- Developing the digital competencies of all educational stakeholders;

- Less negative influence from surrounding people, decrease in stress levels and psychological comfort for less outgoing and socially awkward students;

- Challenge to teachers' professional development;

- Using social media during the teaching and learning process;

- Involvement of parents in the teaching and learning process;

- Opportunity "not to lose" students and accessibility to education during the lockdown;

- Increase in the stress resilience of teachers;

- Teaching assistance to parents from different types of households.

Among the problems of distance learning, the respondents of the study most often identified the following:

- Social (digital) gap since not everyone has fully-featured access to education;

- Decrease in social contacts and disruption to horizontal and informal connections;

- Insufficient technical literacy of teachers;

- Non-applicability of distance teaching to low-performing students, students with health limitations (the objectives of providing the required conditions for teaching students with special needs and teaching according to personalized plans have not been achieved);

- No adequate tools for distance teaching of primary school students;

- Insufficient technical resources of households (even in well-to-do families);

- Variety and quality of educational applications and resources;

- Variety of technical devices;

- Decrease in the monitoring of the learning process;

- Disruption to communication and the inability of schools to control situations inside students' families;

- Family conflicts due to distance learning; 
- Inability to arrange fully-featured learning activities;

- Decrease in teachers' and schools' influence on students' upbringing;

- Incompliance with the safety rules by students;

- Decrease in the number of lessons and exercises that involve handwork (Fine Arts, Technology, manual labor, writing, etc.);

- Impossibility of transferring part of the educational content online (for Physical Education, Biology, Physics, Music, etc.);

- Increase in teachers' workload due to solving new digital tasks by old methods;

- Difficulties in providing psychological assistance;

- Support of students during "hard" times of their studies (1st, $9^{\text {th }}$, and 11th grades, etc.)

- Direct involvement of parents in the learning process;

- New types of conflict relationships (bullying of teachers by students), cyber threats;

- Increase in the number of queries by parents;

- Technical alignments for distance learning (camera angle, quality of sound, screen image, connection, video footage).

\subsection{Marketplace of Educational Applications and Internet Resources}

Another task of this study was to analyze the marketplace of educational applications and Internet resources. All educational applications and resources can be conventionally divided into (a) digital educational platforms (libraries and digital content, LMS, digital sets of problems), and (b) tools that perform specific teachers' tasks (digital tools for video streaming, cloud storage solutions, survey and test tools, groups of subject-based digital tools). The key problems of the operating marketplace include the compatibility of applications and services with different devices, the wide diversity (problem of choice), and the focus on the teacher instead of the student. Another marketplace problem that will emerge in the future and affect the accessibility of education is the problem of continuous updating of the learning content.

\subsection{Violation of the Constitutional Rights of Students to the Accessibility of Education during Distance Learning}

The Federal Law "On education in the Russian Federation" provides the rights, duties, and responsibilities of parents in the sphere of education. Article 44 of defines the following rights to choose the mode of receiving education and the format of learning: the language of instruction, optional and elective subjects, and courses or disciplines according to the student's preference. Article 34 of the Federal Law "On education in the Russian Federation" No. $\$ 3-273$ secures the right of students to be provided with the learning conditions according to their health condition, and instruction according to individual learning plans.

The situation of the pandemic and the forced shift to distance learning was a violation of these rights since it was impossible to choose an appropriate learning mode. Children with health limitations were also unable to select a learning mode or were left out of the educational process.

The following categories of children can be defined as at-risk groups during distance learning:

1. Children from households with two or more children of school age;

2. Children from low-income households;

3. Children in homeschooling;

4. Orphans and children without parental care;

5. Children with health limitations;

6. Children enrolled in sports schools.

The analysis of the problems and barriers to distance learning allows for concluding that technological innovations become a barrier to the accessibility of education for the following people:

- All children in case educational services fail due to a large number of simultaneous users, and/or fail to update content, or offer paid content or services; 
- $\quad$ Children residing far away from large cities or without access to the Internet;

- Children that are not equipped with modern devices that allow them to connect to distance lessons and/or their own workplace;

- Children whose health conditions limit or forbid the use of digital devices.

The barrier of social factors obstructs access to quality education for children, as follows:

- - When parents cannot assist their children in distance learning, students' self-learning skills are not developed;

- - When distance learning is the only form of providing instruction.

The barrier of digital didactics, the lack of teachers' digital competencies, is a barrier to accessible education for all children without exception.

An important factor of education accessibility during distance learning is the factor of motivating students to study and the issue of parents' and schools' responsibilities to develop such motivation.

5.4. Developing Efficient, Legal, Organizational, Informational, and Methodical Measures, Tools to Ensure the Quality of Distance Education and Personal Data Protection during Learning

The results of the study allow for defining the following suggestions to increase the efficiency of distance learning:

Consultancy Support

1. Swift technical consultancy services to solve technical issues and the expansion of technical support services;

2. In-person technical support for teachers (installing required software on personal teachers' PCs);

3. Establishing a nationwide service that provides free assistance for various issues and accumulates the best practices from successful work experiences and/or a platform for experience exchanges between practicing teachers;

4. Establishing/developing psychological counseling services;

5. Establishing support services in case of cyber threats.

Teacher Training and Work Organization

1. Updating the content of in-service training programs for teachers (basic technical skills, demonstrating special aspects of the work with free-access software, platforms in the distance mode); the organization of group work on the Internet; technologies of reverse teaching; technologies and content of e-lessons; technologies of distance instruction of children with health limitations; Internet etiquette;

2. Developing a vocabulary of distance learning terms;

3. Modernization and replacement of outdated equipment;

4. Developing normative documents that regulate distance learning (definition of the optimal duration of e-lessons, definition of the remuneration scheme for teachers teaching in the distance mode, etc.);

5. Ensuring free access to the Internet;

6. Ensuring the security of teachers and school leaders during the difficult period of the pandemic risks and restructuring the teaching process from the supervising agencies' side;

\section{Educational Platforms}

1. Increasing the performance of services and platforms to ensure the simultaneous work of a large number of users (from several hundreds to millions);

2. Quality and performance evaluation of suggested educational resources, platforms, and applications;

3. Developing services, platforms, and applications for students and teachers with health limitations;

4. Creating repositories of digital tasks, such as home tasks and special environments to solve them, and digital interactive multimedia textbooks (as opposed to static textbooks); 
5. Defining an optimal platform to conduct the whole process of instruction and supplementary learning, and so forth;

6. Providing schools with an option to select platforms ("linear stories do not work well either technically or logically");

Work with Parents

1. Delivering training programs to develop planning and self-support skills (for both parents and children);

2. Organization of explanatory and awareness-raising activities for parents, such as based on the support measures offered by the Department of Education and Science of Moscow;

3. Provision of technical devices (laptops, smartphones) and product kits for multi-child and low-income families;

4. On-stream monitoring of issues and fast feedback;

5. Developing systems and rules for interacting on the Internet;

6. Involving child protection services in solving issues of distance learning.

Organization of Distance Learning of Children

1. Evaluating the maximum time allowed for children to work with electronic devices for different age groups and for children with health limitations or disabilities;

2. Developing quality criteria for distance learning;

3. Forbidding to organize summer vacation or the rehabilitation of children using distance technologies;

4. Taking into account the interests of children with health limitations on par with other students;

5. Delivery of a blended or hybrid learning model.

Mandatory distance instruction of students hugely affects the existing ideas of learning, family lifestyles, and customary norms of living, which demands explication to all educational stakeholders, and psychological, organizational, and methodical support [30,31]. This study can serve as a basis for the development of new approaches to education policy in order to ensure children's rights to education in the case of distance learning.

\section{Conclusions}

The pandemic has necessitated remote work and distance education and provoked ambivalent changes in the development of social institutions. On the one hand, digital opportunities have received a very powerful impetus for development. The development of the digital tracking of various educational processes in just a few months of crisis has advanced further than during the previous five years. Schools and teaching staff, who always take a cautious approach toward accepting changes, not only mastered educational IT technologies and resources but in a such difficult situation and helped schoolchildren to complete the academic year successfully. The procedures and regulations for distance learning have been created, and various models of combined traditional and mandatory elements of the educational process with new ones-creative, dynamic, and freer-have been pilot-tested.

On the other hand, many functions of schools as social institutions were under threat, including the ones that affect the processes of socialization and social adaptation of children. Educational spaces are designed to neutralize the negative impact of the inequality of wealth on the opportunity to get an education. However, the "school dispersion" into families' home spaces during the pandemic exacerbated this problem. The lack of technical capabilities affected the quality of access to teaching materials and tasks, access to help from the teacher, and participation in teamwork. The use of computer technology and work at the monitor threaten the pupils' health (for example, eyesight and posture can be damaged, and hypodynamia can occur). The difficulties with arranging workspaces in apartments determine the depth and quality of children's involvement in the learning process. 
The structure of learning interactions underwent great pressure due to the sharply increased demand for an individual approach to the pupils, especially to those with health limitations [32-36]. The teacher's work and his/her communication with the pupils have become unprecedentedly open to the attention of parents. The latter were forced to be strongly involved in the learning process, and this participation was not always justified, effective, or useful.

In the period before the pandemic, the possibility of a family form of education had been perceived as a certain privilege available to few families. By analogy to freelancing, this form of education seemed not only comfortable but almost ideal for children. The spring of 2020 showed the negative sides of this practice, as follows:

- High requirements for the children's self-dependence, and their ability to manage their time and workload;

- High requirements for the quality of intra-family relations; the commitment of parents to be a source of support for their children, their ability to manage their emotional state and psychological stability and to deal with their own and their child's burnout and stress;

- The need to create comfortable conditions for learning to match the educational and work obligations of all family members, and to manage the balance of work and rest;

- The requirements for the technical literacy of parents, for their ability to solve technical problems, as well as to form a sufficiently effective culture of cybersecurity;

- The skills and commitment of parents to build constructive relationships with the teachers and the school.

The crisis experience has shown that the reality of distance learning turned out to be far from ideal. It is no wonder that both parents and children, for the most part, defended the intramural form of education in the autumn of 2020. However, the study results show that distance learning is supported by more parents than one might think.

Nevertheless, during the distance learning process, children managed to get used to the new, productive formats of blended learning (they did not appear everywhere, but they existed in one form or another and had the edge over the traditional format of knowledge broadcasting). We saw the greatest support for distance learning among teenagers (Grades 7-9). In some of the pupils' questionnaires, there were fears that with the return to school, this "thaw" in the learning formats would disappear. This caused a negative reaction, first of all, among those who saw that it was possible to learn in a different way, to get different homework, and to interact in a new way in the classroom. This is the main challenge to today's education-will schools be able to rework and integrate all the achievements and breakthroughs of distance learning? The demand for this has already been formed. In this regard, we can conclude that upon the implementation of distance learning, it is necessary to take into account the threats and risks that it entails, as follows:

1. Technological innovation barrier-the provision of modern equipment to students (computers, tablets, cameras, microphones, printers, scanners, etc.), technical problems of connecting to digital services, Internet accessibility, operability and availability of educational systems and applications, fast connection to quality content, the need for several studying areas in one apartment, and so forth;

2. Social factor barrier-shifting social roles, weak dialogue between schools and parents, specifics of the parents' work activities, violation of social interaction, and the financial status of households;

3. Physical and psychological health barrier-fear that this situation will last forever, suspense due to the novelty of the situation, distracted attention due to many distractions at home, fear of the futility of efforts in achieving the effectiveness of learning in the classroom, decreased motivation of children, teachers' emotional burnout, problems of domestic violence in a confined space during the period of self-isolation, lack of social stability, problems of changing one's life routine, problems of official confirmation of diagnoses, and problems of deteriorating health parameters; 
4. Digital didactics barrier-the archaism of the existing education system, the impossibility of transferring content, technologies, and methods of traditional didactics to the online mode, and low levels of teachers' digital competence;

5. Legal regulation barrier - the regulation of the teachers' work time, their functional duties, the creation of network schools and the implementation of network educational programs, the interaction of the participants of the educational process, the security and protection of personal data, and the control and assessment of educational achievements.

The constitutional right to education is a fundamental right of the individual on which the realization of other human rights depends. Education is a universal global good and the most powerful engine of human development as a civilization.

The COVID-19 pandemic has led to a global transformation of the educational space, and information and telecommunication technologies have become ingrained in modern teaching and upbringing practices. Along with the challenges and difficulties, the COVID-19 pandemic has opened new opportunities for the educational environment, including the development of new approaches to educational practices, the progressive growth of digital methods and approaches in the implementation of educational activities, and changing the traditional education paradigm. However, to improve the efficiency of organizing teachers' labor, it is necessary to develop new digital didactics, describe new methods and tools, and enhance the teachers' proficiency.

\section{Limitations and Future Research}

The methodological limitations of our study can be related to both the sample of the study and the methodological tools. The sample of the study was provided at the level of a municipality of Moscow. The obtained results of the study do not guarantee the validity of the data for subjects of educational relations (children, parents, and teachers) in other cities of Russia. However, despite this limitation, the sample meets the methodological principles of organizing and conducting a sociological survey. The next limitation is related to the tools used. Since in-depth interviews were used in the study, the interpretation of the results obtained is inevitably associated with the subjective position of the interviewer. However, in our study, this limitation was leveled by the results of a large-scale survey, which confirmed the obtained data of the in-depth interviews. It is also possible to designate a limitation of our study associated with the need for a comprehensive analysis of the social situation of the development of educational relations among children, teachers, and parents in the dynamics of the transformation of online learning mechanisms. This aspect will be considered in our further research.

Author Contributions: S.N.V.- -development of the concept and design of the study; preparation of the manuscript; critical revision of the manuscript for important intellectual content; approval of the version of the manuscript to be published. I.V.V., I.A.K., E.Y.P., and V.B.S.- development of the research plan; data collection, analysis, and interpretation; preparation of the manuscript; editing of the manuscript; revision of the manuscript for important intellectual content. All authors have read and agreed to the published version of the manuscript.

Funding: This research received no external funding. 
Institutional Review Board Statement: We were guided by the standards and recommendations of several associations that develop standards in the field of empirical social research and update them regularly: (1) AAPOR-American Association of Public Opinion Researchers (https:/ / www.aapor.org/ Standards-Ethics/AAPOR-Code-of-Ethics.aspx, date of accesses 10 November 2021); (2) ESOMAR is an international community of researchers and data collection and analysis specialists who have committed themselves to comply with the provisions of the ICC/ESOMAR International Code; it was established in 1948; (3) OIROM is a Russian professional association of research companies established in 2003 and also follows the ICC/ESOMAR code. (https: / / oirom.ru/standarts, (date of accesses 10 November 2021); (4) ROS, the Russian Society of Sociologists, is the largest association in the country (the Soviet Sociological Association since 1958 and Russian Society of Sociologists since 1989) and has developed the Professional Code of a Sociologist with the participation of 75 regional branches (https: / / ssa-rss.ru/index.php?page_id=84 (date of accesses 10 November 2021)).

Informed Consent Statement: Written informed consent has been obtained from the respondent(s).

Data Availability Statement: MDPI Research Data Policies rules have been checked. The study was prepared following these rules.

Conflicts of Interest: The authors declare no conflict of interest.

\section{References}

1. Policy Brief: Education During COVID-19 and beyond (2020, August). United Nations. Electronic Resource. Available online: https://www.un.org/development/desa/dspd/wp-content/uploads/sites/22/2020/08/sg_policy_brief_covid-19_and_ education_august_2020.pdf (accessed on 22 May 2021).

2. Caliskan, S.; Guney, Z.; Sakhieva, R.G.; Vasbieva, D.G.; Zaitseva, N.A. Teachers' views on the availability of web 2.0 tools in education. Int. J. Emerg. Technol. Learn. 2019, 14, 70-812. [CrossRef]

3. Bayanova, A.R.; Sabaeva, E.K.; Sakhipova, Z.M.; Zatsepina, M.B.; Tararina, L.I.; Votinov, A.A.; Ilkevich, K.B. Educational Environment Ecology as Factor of University Teacher Health Saving in Context of Education and Science Reforms in Modern Russia. Ekoloji 2019, 28, 4937-4941.

4. Iivari, N.; Sharma, S.; Venta-Olkkonen, L. Digital transformation of everyday life-how COVID-19 pandemic transformed the basic education of the young generation and why information management research should care? Int. J. Inf. Manag. 2020, 55, 102183. [CrossRef] [PubMed]

5. Vachkova, S.N.; Petryaeva, E.Y.; Kupriyanov, R.B.; Suleymanov, R.S. School in Digital Age: How Big Data Help to Transform the Curriculum. Information 2021, 12, 33. [CrossRef]

6. Salakhova, V.B.; Erofeeva, M.A.; Pronina, E.V.; Belyakova, N.V.; Zaitseva, N.; Ishmuradova, I.I. State regulation and development of digital educational platforms. World J. Educ. Technol. Curr. Issues 2021, 13, 956-966. [CrossRef]

7. Ferguson, D. Anxious Middle-Classes Look to Private Schools after Coronavirus Disruption. 2020. Available online: https:/ /www. theguardian.com/education/2020/jul/26/anxious-middle-classes-look-to-private-schools-after-coronavirus-disruption (accessed on 20 May 2021).

8. The Organisation for Economic Co-operation and Development. OECD Education at a Glance. 2015. Available online: https://www. oecd.org/education/education-at-a-glance-2015.htm (accessed on 20 November 2021).

9. Vachkova, S.N.; Klimov, I.A.; Petryaeva, E.Y.U.; Salakhova, V.B. Results of the Study of the Problem of Observance of the Rights of the Child to the Availability of Education in the Context of the Imple-Mentation of Basic Educational Programs of Primary General and Basic General Education in a Distance Format Duri; Econ-Inform: Moscow, Russia, 2021.

10. Gonzalez-Betancor, S.M.; Lo Pez-Puig, A.J.; Cardenal, M.E. Digital inequality at home. The school as compensatory agent. Comput. Educ. 2021, 168, 104195. [CrossRef]

11. Tang, Y.M.; Ng, G.W.Y.; Chia, N.H.; So, E.H.K.; Wu, C.H.; Ip, W.H. (2021). Application of virtual reality (VR) technology for medical practitioners in type and screen (T\&S) training. J. Comput. Assist. Learn. 2021, 37, 359-369.

12. Srijamdee, K.; Pholphirul, P. Does ICT familiarity always help promote educational outcomes? Empirical evidence from PISA-Thailand. Educ. Inf. Technol. 2020, 25, 2933-2970. [CrossRef]

13. Beaunoyer, E.; Dupere, S.; Guitton, M.J. COVID-19 and digital inequalities: Reciprocal impacts and mitigation strategies. Comput. Hum. Behav. 2020, 111, 106424. [CrossRef]

14. The Organisation for Economic Co-operation and Development. PISA 2018 Database. 2020. Available online: https://www.oecd. org/pisa/data/2018database/ (accessed on 20 November 2021).

15. Tang, Y.M.; Chen, P.C.; Law, K.; Wu, C.H.; Lau, Y.Y.; Guan, J.; He, D.; Ho, G. (2021). Comparative analysis of Student's live online learning readiness during the coronavirus (COVID-19) pandemic in the higher education sector. Comput. Educ. 2021, $168,104211$. [CrossRef]

16. Saikkonen, L.; Kaarakainen, M.T. Multivariate analysis of teachers' digital information skills-The importance of available resources. Comput. Educ. 2021, 168, 104206. [CrossRef] 
17. Van Lancker, W.; Parolin, Z. COVID-19, school closures, and child poverty: A social crisis in the making. Lancet Public Health 2020, 5, 243-244. [CrossRef]

18. Ministère de l'Education Nationale de la Jeunesse et des Sports. Ma Classe à la Maison: Mise en Euvre de la Continuité Pédagogique. 2021. Available online: https:/ / www.education.gouv.fr/ma-classe-la-maison-mise-en-oeuvre-de-la-continuitepedagogique-289680 (accessed on 20 May 2021).

19. The National Literacy Trust. Adult Literacy Information on Adult Literacy in the UK. 2021. Available online: https:/ / literacytrust. org.uk/parents-and-families/adult-literacy/ (accessed on 20 November 2021).

20. Sistema de Medios Publicos. RTVC y Ministerio de Educación Nacional. 2021. Available online: https://www.rtvc.gov.co/ noticia/rtvc-ministerio-educacion-alianza-emitir-contenidos-educativos-covid19 (accessed on 20 November 2021).

21. Saprykina, D.I.; Volokhovich, A.A. Research E Expertise to Make a Difference in Education E Beyond; High School of Economics: Moscow, Russia, 2020.

22. United Nations Educational, Scientific and Cultural Organization. Education: From Disruption to Recovery. 2021. Available online: https:/ / ru.unesco.org/covid19/educationresponse (accessed on 20 November 2021).

23. Blinov, S. Education under Attack from Coronavirus: Difficulties of Schools and Opinions of Teachers. 2020. Available online: https:/ /activityedu.ru/Blogs/analytics / obrazovanie-pod-udarom-koronavirusa-trudnosti-shkol-i-mneniya-pedagogov / (accessed on 20 May 2021).

24. Adamovich, K.A.; Kapuza, A.V.; Gorbunova, A.A. Primary School Students and Their Educators in the Digital Environment. 2020. Available online: https://ioe.hse.ru/data/2020/06/19/16-07509887/\%D0\%A4\%D0\%9E\%205(30)\%20\%D1\%8D\%D0\%BB\% D0\%B5\%D0\%BA \%D1\%82\%D1\%80\%D0\%BE\%D0\%BD\%D0\%BD\%D1\%8B\%D0\%B9.pdf (accessed on 20 May 2021).

25. Tarasova, N.V.; Pastukhova, I.P.; Pestrikova, S.M. How Does the Transfer of the Educational Process into a Distance Mode Affect Educational Results Now and Will Affect in the Future? Kazan: RANEPA-National School of Public and Business Administration. 2020. Available online: https:// firo.ranepa.ru/novosti/105-monitoring-obrazovaniya-na-karantine/803-tarasova-ekspertiza (accessed on 17 October 2021).

26. Uvarov, A.Y.U.; Frumin, I.D. Difficulties and Prospects of Digital Transformation of Education. A Series of Collective Monographs: Russian Education: Achievements, Challenges, Prospects; Higher School of Economics: Moscow, Russia, 2019.

27. Suarez-Lopez, J.R.; Cairns, M.R.; Sripada, K.; Quiros-Alcala, L.; Mielke, H.W.; Eskenazi, B.; Etzel, R.A.; Kordas, K. COVID-19 and children's health in the United States: Consideration of physical and social environments during the pandemic. Environ. Res. 2021, 197, 111160. [CrossRef]

28. Knudsen, E.I.; Heckman, J.J.; Cameron, J.L.; Shonkoff, J.P. Economic, neurobiological, and behavioral perspectives on building America's future workforce. Proc. Natl. Acad. Sci. USA 2006, 103, 10155-10162. [CrossRef]

29. Malik, F.; Marwaha, R. Developmental Stages of Social Emotional Development in Children; StatPearls Publishing: Treasure Island, FL, USA, 2020.

30. Akhmadieva, R.S.; Mikhaylovsky, M.N.; Simonova, M.M.; Nizamutdinova, S.M.; Prokopyev, A.I.; Ostanina, S.S. Public relations in organizations in sportsman students view: Development of management tools or healthy and friendly relations formation. J. Hum. Sport Exerc. 2021, 16, 1272-1279.

31. Tugun, V.; Bayanova, A.R.; Erdyneeva, K.G.; Mashkin, N.A.; Sakhipova, Z.M.; Zasova, L.V. The Opinions of Technology Supported Education of University Students. Int. J. Emerg. Technol. Learn. 2020, 15, 4-14. [CrossRef]

32. Yazcayir, G.; Gurgur, H. Students with Special Needs in Digital Classrooms during the COVID-19 Pandemic in Turkey. Pedagogical Res. 2021, 6, em0088. [CrossRef]

33. Nam-Nguyen, V.; Truong, T.T.; Ly, D.T.; Dagamac, N.H.A. Perceptions of Environmental Science and Management Students on Synchronous Online Teaching of Environmental Policies: Learning Experience from Southeast Asian Cohort. Pedagogical Res. 2021, 6, em0084. [CrossRef]

34. Burns, E.A.; Manouchehri, B. Reconnecting Children with Nature: Foundation and Growth of the Nature Schools Movement in Iran. Interdiscip J Env Sci Ed. 2021, 17, e2244. [CrossRef]

35. Salakhova, V.B.; Masalimova, A.R.; Belyakova, N.V.; Morozova, N.S.; Osipova, N.V.; Prokopyev, A.I. Competitive Teacher for Higher Education: Risk-Based Models of its Development. Eurasia J. Math. Sci. Technol. Educ. 2021, 17, em2021. [CrossRef]

36. Tavukcu, T.; Kalimullin, A.; Litvinov, A.; Shindryaeva, N.; Abraukhova, V.; Abdikeev, N. Analysis of Articles on Education and Instructional Technologies (Scopus). Int. J. Emerg. Technol. Learn. 2020, 15, 108-120. [CrossRef] 